\title{
Editorial: Emerging zoonoses: eco-epidemiology, involved mechanisms, and public health implications
}

\author{
Rubén Bueno-Mari ${ }^{1 *}$, A. Paulo Gouveia Almeida ${ }^{2,3}$ and Juan Carlos Navarro ${ }^{4}$ \\ ${ }^{1}$ Entomology and Pest Control Laboratory, Cavanilles Institute of Biodiversity and Evolutionary Biology (ICBiBE), University of \\ Valencia, Valencia, Spain, ${ }^{2}$ Global Health and Tropical Medicine (GHTM), Instituto de Higiene e Medicina Tropical, Universidade \\ Nova de Lisboa, Lisbon, Portugal, ${ }^{3}$ University of Pretoria, Pretoria, South Africa, ${ }^{4}$ Instituto de Zoología y Ecología Tropical, \\ Universidad Central de Venezuela, Caracas, Venezuela
}

Keywords: zoonoses, infectious diseases, infectious diseases epidemiology, editorial, one health

Zoonoses are currently considered as one of the most important threats for Public Health worldwide. Zoonoses can be defined as any disease or infection that is naturally transmissible from vertebrate or invertebrate animals to humans and vice-versa. Approximately, $75 \%$ of recently emerging infectious diseases affecting humans are diseases of animal origin; approximately, $60 \%$ of all human pathogens are zoonotic. All types of potential pathogenic agents, including viruses, parasites, bacteria, and fungi, can cause these zoonotic infections. From the wide range of potential vectors of zoonoses, arthropods are probably those of major significance due to their abundance, high plasticity, adaptability, and coevolution to different kinds of pathogens, high degrees of synanthropism in several groups, and difficulties to apply effective programs of population control. Although ticks, flies, sandflies, cockroaches, bugs, and fleas are excellent vectors capable of transmitting viruses, parasites, and bacteria, undoubtedly mosquitoes are the most important human disease vectors, while ticks are the most important vectors of pathogens in domestic production animals. Mosquito borne diseases like malaria, equine encephalitis, or West Nile are zoonoses with increasing incidence in the last years in tropical and temperate countries. All these zoonoses are thoroughly discussed in the Research Topic (1-5). Moreover, several researches focused on new tools to fight against Dengue vectors (6), studies about mosquito biodiversity (7), or novel modeling techniques based on climatic factors to predict vector's incidence (8) can also be found in our compilation of research works related with zoonoses. Although it is well known that mosquitoes are the major vectors worldwide, probably ticks and tick-borne diseases are those that have aroused higher interest in epidemiologists and medical entomologists in recent years $(9-12)$.

The problems related with zoonoses have different significance in developed and undeveloped countries. One example of a vector-borne disease relatively easy to combat with current pharmacological, preventive, and vector control tools but with a dramatic incidence in Central and South America is Chagas disease or American trypanosomiasis (13-19). In Africa and Asia, other neglected diseases like leishmaniasis or African trypanosomiasis have serious impact on human populations locally (20-22).

Not all zoonoses are vector borne, vertebrates can also transmit serious zoonoses, highlighting the role of some carnivorous animals in rabies dissemination, the spread of rodent borne diseases in several rural and urban areas, or some transmissible bacteria in cattle and other livestock (23).

According to WHO, FAO, and OIE guidelines, an emerging zoonotic disease can be defined as a zoonosis that is newly recognized or newly evolved, or that has occurred previously but shows an increase of incidence or expansion in geographical, host, or vector range. There are many factors that can provoke or accelerate the emergence of zoonoses, such as environmental changes, habitat modifications, variations of human and animal demography, pathogens and vectors anomalous mobi-

lization related with human practices and globalization, such as the introduction of exotic mosquito

Navarro JC (2015) Editorial: Emerging zoonoses: eco-epidemiology, involved mechanisms, and public health implications.

Front. Public Health 3:157. doi: 10.3389/fpubh.2015.00157 
species of which Aedes albopictus is the paradigm, deterioration of the strategies of vector control, or changes in pathogen genetics (24-26). To reduce Public Health risks from zoonoses, it is absolutely necessary to acquire an integrative perspective that includes the study of the complexity of interactions among humans, animals, and environment in order to be able to fight against these issues of primary interest for human health, hence the new "One Health" approach. In any case, although zoonoses represent significant public health threats, many of them still remain as neglected diseases and consequently are not prioritized by some national or international health organisms.

The aim of this Research Topic is to cover all related fields with zoonoses, including basic and applied researches, approaches to

\section{References}

1. Hernández-Triana LM, Jeffries CL, Mansfield KL, Carnell G, Fooks AR, Johnson N. Emergence of West Nile virus lineage 2 in Europe: a review on the introduction and spread of a mosquito-borne disease. Front Public Health (2014) 2:271. doi:10.3389/fpubh.2014.00271

2. Neira MV, Mahmood F, Reisen WK, James CBL, Romoser WS. Comparative study of the pathological effects of western equine encephalomyelitis virus in four strains of Culex tarsalis Coquillett (Diptera: Culicidae). Front Public Health (2014) 2:184. doi:10.3389/fpubh.2014.00184

3. Himeidan YE, Kweka EJ, Mahgoub MM, El Rayah EA, Ouma JO. Recent outbreaks of rift valley fever in east africa and the middle east. Front Public Health (2014) 2:169. doi:10.3389/fpubh.2014.00169

4. Prow NA, Hewlett EK, Faddy HM, Coiacetto F, Wang W, Cox T, et al. The Australian public is still vulnerable to emerging virulent strains of West Nile virus. Front Public Health (2014) 2:146. doi:10.3389/fpubh.2014.00146

5. Ramasamy R. Zoonotic malaria - global overview and research and policy needs. Front Public Health (2014) 2:123. doi:10.3389/fpubh.2014.00123

6. Kumar S, Mishra M, Wahab N, Warikoo R. Larvicidal, repellent, and irritant potential of the seed-derived essential oil of Apium graveolens against dengue vector, Aedes aegypti L. (Diptera: Culicidae). Front Public Health (2014) 2:147. doi:10.3389/fpubh.2014.00147

7. Berti J, Guzmán H, Estrada Y, Ramírez R. New records of mosquitoes (Diptera: Culicidae) from Bolívar State in South Eastern Venezuela, with 27 new species for the state and 5 of them new in the country. Front Public Health (2015) 2:268. doi:10.3389/fpubh.2014.00268

8. Swart A, Ibañez-Justicia A, Buijs J, van Wieren SE, Hofmeester TR, Sprong $\mathrm{H}$, et al. Predicting tick presence by environmental risk mapping. Front Public Health (2014) 2:238. doi:10.3389/fpubh.2014.00238

9. Tijsse-Klasen E, Koopmans MPG, Sprong H. Tick-borne pathogen - reversed and conventional discovery of disease. Front Public Health (2014) 2:73. doi:10. 3389/fpubh.2014.00073

10. James MC, Gilbert L, Bowman AS, Forbes KJ. The heterogeneity, distribution, and environmental associations of Borrelia burgdorferi sensu lato, the agent of lyme borreliosis, in Scotland. Front Public Health (2014) 2:129. doi:10.3389/ fpubh.2014.00129

11. Rizzoli A, Silaghi C, Obiegala A, Rudolf I, Hubálek Z, Földvári G, et al. Ixodes ricinus and its transmitted pathogens in urban and peri-urban areas in Europe: new hazards and relevance for public health. Front Public Health (2014) 2:251. doi:10.3389/fpubh.2014.00251

12. Eremeeva ME, Dasch GA. Challenges posed by tick-borne rickettsiae: ecoepidemiology and public health implications. Front Public Health (2015) 3:55. doi:10.3389/fpubh.2015.00055

13. Finol HJ, Roschman-González A. Ultrastructural study on tissue alterations caused by trypanosomatids in experimental murine infections. Front Public Health (2014) 2:75. doi:10.3389/fpubh.2014.0007

14. Gonzalez-Britez NE, Carrasco HJ, Martínez Purroy CE, Feliciangeli MD, Maldonado M, López E, et al. Genetic and morphometric variability of Triatoma sordida (Hemiptera: Reduviidae) from the eastern and western regions of Paraguay. Front Public Health (2014) 2:149. doi:10.3389/fpubh.2014.00149

15. García-Alzate R, Lozano-Arias D, Reyes-Lugo RM, Morocoima A, Herrera L, Mendoza-León A. Triatoma maculata, the vector of Trypanosoma cruzi, control measures, explanations of new theories or observations, opinion articles, reviews, etc. To deeply discuss these issues, a holistic and integrative point of view is obviously needed and guided by the "One Health" strategy. Editors are very proud to say that this ambitious goal for the Research Topic has been accomplished, thanks to the collaboration of researchers specialized in different fields as medical and veterinary entomologists, parasitologists, veterinarians, virologists, zoologists, microbiologists, ecologists, evolutionary biologists, and medicals specialized in epidemiology, public health, and animal health. The participation of multiple contributors and a multidisciplinary approach have been most important to comply with a knowledge demand of this issue of first-rate of scientific and medical interest.

in Venezuela. Phenotypic and genotypic variability as potential indicator of vector displacement into the domestic habitat. Front Public Health (2014) 2:170. doi:10.3389/fpubh.2014.00170

16. Gómez-Melendro EN, Hernández C, González-Uribe C, Brochero H. First record of Triatoma maculata (Erichson, 1848) (Hemiptera: Reduviidae: Triatomini) in the municipality of Riohacha, La Guajira - Colombia. Front Public Health (2014) 2:219. doi:10.3389/fpubh.2014.00219

17. Esteve-Gassent MD, Pérez de León AA, Romero-Salas D, Feria-Arroyo TP Patino R, Castro-Arellano I, et al. Pathogenic landscape of transboundary zoonotic diseases in the Mexico-US border along the Rio Grande. Front Public Health (2014) 2:177. doi:10.3389/fpubh.2014.00177

18. Herrera L. Trypanosoma cruzi, the causal agent of Chagas disease: boundaries between wild and domestic cycles in Venezuela. Front Public Health (2014) 2:259. doi:10.3389/fpubh.2014.00259

19. Urdaneta-Morales S. Chagas' disease: an emergent urban zoonosis. The Caracas Valley (Venezuela) as an epidemiological model. Front Public Health (2014) 2:265. doi:10.3389/fpubh.2014.00265

20. Darvishi M, Yaghoobi-Ershadi MR, Shahbazi F, Akhavan AA, Jafari R, Soleimani H, et al. Epidemiological study on sand flies in an endemic focus of cutaneous leishmaniasis, Bushehr city, southwestern Iran. Front Public Health (2015) 3:14. doi:10.3389/fpubh.2015.00014

21. Dhiman RC. Emerging vector-borne zoonoses: eco-epidemiology and public health implications in India. Front Public Health (2014) 2:168. doi:10.3389/ fpubh.2014.00168

22. Okello AL, Welburn SC. The importance of veterinary policy in preventing the emergence and re-emergence of zoonotic disease: examining the case of human African trypanosomiasis in Uganda. Front Public Health (2014) 2:218. doi:10.3389/fpubh. 2014.00218

23. Rodríguez-Hidalgo RI, Contreras-Zamora J, Benitez Ortiz W, GuerreroViracocha K, Salcan-Guaman H, Minda E, et al. Circulating strains of Brucella abortus in cattle in Santo Domingo de los Tsáchilas Province - Ecuador. Front Public Health (2015) 3:45. doi:10.3389/fpubh.2015.00045

24. Ortiz-Rodriguez MP, Villamil-Jimenez LC. Influenza: environmental remodeling, population dynamics, and the need to understand networks. Front Public Health (2014) 2:153. doi:10.3389/fpubh.2014.00153

25. Savić S, Vidić B, Grgić Z, Potkonjak A, Spasojevic L. Emerging vector-borne diseases - incidence through vectors. Front Public Health (2014) 2:267. doi:10. 3389/fpubh.2014.00267

26. Braks M, Medlock JM, Hubalek Z, Hjertqvist M, Perrin Y, Lancelot R, et al. Vector-borne disease intelligence: strategies to deal with disease burden and threats. Front Public Health (2014) 2:280. doi:10.3389/fpubh.2014.00280

Conflict of Interest Statement: The authors declare that the research was conducted in the absence of any commercial or financial relationships that could be construed as a potential conflict of interest.

Copyright (C) 2015 Bueno-Marí, Almeida and Navarro. This is an open-access article distributed under the terms of the Creative Commons Attribution License (CC BY). The use, distribution or reproduction in other forums is permitted, provided the original author(s) or licensor are credited and that the original publication in this journal is cited, in accordance with accepted academic practice. No use, distribution or reproduction is permitted which does not comply with these terms. 